\title{
Analysis of Morphological and Mechanical Behaviors of Bamboo Flour Reinforced Polypropylene Composites
}

\author{
Netra L. Bhandari ${ }^{1,2}$, Sabu Thomas ${ }^{3}$, Chapal K. Das ${ }^{3}$ and Rameshwar Adhikari ${ }^{1}$ \\ ${ }^{1}$ Central Department of Chemistry \\ Tribhuvan University \\ Kirtipur, Kathmandu \\ ${ }^{2}$ Department of Chemistry, Tri-Chandra Multiple Campus \\ Ghantaghar, Kathmandu \\ ${ }^{3}$ School of Chemical Sciences, Mahatma Gandhi University \\ Kottayam, Kerala, India \\ ${ }^{4}$ Materials Science Centre, Indian Institute of Technology (IIT) \\ Kharagpur, India \\ e-mail: nepalpolymer@yahoo.com
}

\begin{abstract}
In this paper, the bamboo flour (BF) reinforced polypropylene (PP) composites were studied with special attention to morphology of the composites and the effectiveness of chemically modified fillers to improve their mechanical properties. The composites of polypropylene with neat bamboo flour (BF) and treated bamboo flour (TBF) in different proportions were prepared by melt mixing followed by compression molding. The samples were characterized by Fourier Transform Infrared (FTIR) spectroscopy, Scanning Electron Microscopy (SEM), tensile testing and water absorption testing. The results show that the alkali treated BF is compatible with polypropylene matrix than the neat one as the effects are reflected in the morphological features of the composites and their tensile mechanical properties.
\end{abstract}

Key words: eco-friendly materials, mechanical properties, natural fibers reinforced plastics, polymer composites

\section{Introduction}

Nowadays, polymer composites reinforced with wood flour have become very interesting area of research mainly due to the possibility of developing ecofriendly and cost effective composite materials. The composite materials offer a wide variety of mechanical, physical, optical, and chemical properties usually better than the individual components (Bledzki \& Sperber 2008). Wood polymer composites are generally cheaper, easy to treat, easily processible, relatively better dimensional stability, stiffer and lower density in comparison to mineral fillers, easily reproducible and environmentally friendly (Bledzki \& Gassan 1999).

In wood polymer composites (WPCs), different types of wood flour of various size and concentrations are used as fillers (Bogoeva-Gaceva et al. 2007). The development of wood plastic composites (WPC's) is being the most popular and important field of research because of their high demands in the global market due to many useful properties (Bledzki \& Sperber 2008). The production and use of such materials are increasing day by day. The properties of WPC's basically depend on the type of flour, particle size, chemical treatment and thermoplastic polymers chosen as matrix (Bogoeva-Gaceva et al. 2007). Polypropylene (PP), polyethylene (PE), polyvinyl chloride (PVC), polystyrene (PS), polyethylene terephthalate (PET) and other mixed copolymers are commonly used polymer matrices. Most of the composites are biodegradable to some extent but nowadays works are also being started towards the progress of totally biodegradable polymer composites (Bogoeva-Gaceva et al. 2007).

In wood flour, cellulose is the major constituent. It is an important biopolymer produced in nature by photosynthesis. Cotton fiber is the main source of 
cellulose with more than $95 \%$ by weight. In woody plants, cellulose content is lesser than is associated with lignin and other polysaccharides such as hemicellulose in considerable quantities. Bamboo flour contains $26-43 \%$ cellulose, 30\% hemicellulose and 21-31\% lignin (Saheb et al. 1999, Joseph et al. 1999, Li et al. 2000). The cellulose in wood flour forms the microfibrillar bundles which are compactly held to each other by means of hemicellulose where the lignin provides the mechanical strength (John \& Anadjiwala 2008, Bledzki \& Sperber 2008). The cellulose content in bamboo flour also depends on the plant age and species. Lignin and hemicellulose from bamboo flour are removed by treatment with alkalies and/or sulphites (John \& Anandjiwala 2008, Kumar et al. 2010).

a).

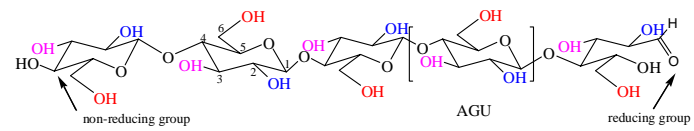

b).

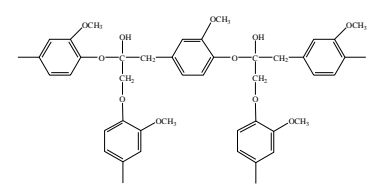

Scheme 1. Molecular structure of a). cellulose and b). lignin

The cellulose chains are organized in crystalline fibrils by inter- and intra-molecular hydrogen bonding (Scheme 1). Due to presence of such networks, it is almost insoluble in water as well as most of other organic solvents but only swells in many polar protic and aprotic liquids (Mormann 2003).

Wood polymer composites (WPCs) are processed with similar technologies that are used in the plastic processing industries like extrusion and injection molding (Sperling 2006). The choice of wood flour as filler and the polymer as matrix determines the process to be applied. The dehydration of the wood, degree of permissible moisture content, size of particles and additives are the decisive factors (Zaini et al. 1996, Razi et al. 1997, Kalaprasad 2004).

The biggest challenge in developing the wood flour reinforced polypropylene is the problem of compatibility in between the hydrophilic fillers and hydrophobic polymers. High water absorption, low moisture resistance and insufficient adhesion to polymer matrix are the main factors responsible for the poor compatibility. The use of suitable compatibilizers or the chemical treatment of filler and matrix would be some alternatives to minimize the problem of compatibility (Rowell 2005, Wu et al. 2000, Nachtigall et al. 2007). The mechanical, morphological and thermal properties of different wood flour (sisal, jute, flex, hemp, kneaf, bamboo, oil palm) of various size and concentration have been studied and reviewed in detail (Adhikari et al. 2012, Zaini et al. 1996, Kalaprasad et al. 2004, Chattopadhayay, 2011). Aim of the study was to study the effectiveness of chemically modified bamboo flour through analyzing morphological and mechanical behaviors of the bamboo flour reinforced polypropylene composites.

This kind of work is very important in Nepal because bamboo is easily available from the local natural resources and such composite materials are environment friendly (Bourmaud \& Baley 2007) and economically viable. The high filler loaded composites are more biodegradable compared with the commercial plastics in one hand and also it helps to reduce the use of commercial plastics on the other.

\section{Methodology}

Fillers: The fillers used for this research was flour of Bambusa nutans (local name: Taru Bans). Fully matured 3 years old bamboo shoots were collected from village nearby the Kathmandu valley. The shoots were chopped into small pieces, dried in sun light for 12 days and powdered by mechanical grinding. The powder was sieved with 350 ìm mess to get the fine flour with uniform particles size.

The flour was dipped in $4 \%$ (w/v) sodium hydroxide solution in water for 8 hours, neutralized by acetic acid and washed many times with distilled water (Kumar, et al. 2010). It was dried in oven at $90^{\circ} \mathrm{C}$ for 8 hours. The objective of chemical treatment was to remove lignin and hemicelluloses from the wood flour. The representative reaction of chemical treatment can be represented as in equation (1).

Wood- $\mathrm{OH}+\mathrm{NaOH} \longrightarrow$ Wood $-\mathrm{O}^{-} \mathrm{Na}^{+}+\mathrm{H}_{2} \mathrm{O}$

Matrix: The polymer used is the isotactic polypropylene (iPP). It is a commercial homopolymer (Moplen PP562N) of Basell Chemical Company having molecular weight of 230,000 g/mol and melt flow index (MFI) of 11g/10 min. The melting point and glass transition temperature of iPP are $208{ }^{\circ} \mathrm{C}$ and $-8{ }^{\circ} \mathrm{C}$, respectively. 


\section{Sample preparation}

The different composition composites of iPP with bamboo flour (iPP/bamboo flour compositions of 80/ 20 and 60/40 by weight) were prepared by melt mixing followed by compression molding. 5 wt.-\% maleic anhydride grafted polypropylene (MA-g-PP; trade name Scona Exxelor ${ }^{\mathrm{TM}}$ PO 1020) was used as compatibilizer.

The required amount of components was mixed in an internal mixture Haake brabender (Plasto Mek) at 170 ${ }^{\circ} \mathrm{C}$ and $50 \mathrm{rpm}$ (rotations per minute) for 10 minutes. The tensile bars were prepared by compression molding at $180^{\circ} \mathrm{C}$ and 120 bar pressure for 2 minutes.

\section{Characterization techniques}

The morphological and mechanical characterizations of the sample were carried out by using different techniques.

Fourier Transform Infrared (FTIR) Spectroscopy: FTIR spectra of solid injection molded samples were recorded in absorbance and transmittance mode using a Bruker Equinox 55 FTIR spectrometer in ATR mode.

Scanning Electron Microscopy (SEM): Scanning electron microscopy (JSM 6300, JEOL) was used to visualise the structural details of the samples. The surfaces were sputtered coated with thin gold film to avoid charging and irradiation damage during the SEM observations.

Mechanical Testing: The mechanical testing was carried out by using universal tensile machine. Tensile bars having 40 x 5.1 x $1.8 \mathrm{~mm}$ size were prepared by compression molding. At least four experiments were performed at a cross head speed of $50 \mathrm{~mm} / \mathrm{min}$ at $23^{\circ} \mathrm{C}$ for each composite sample and the average value was considered for the comparison.

Water Absorption: Water absorption was determined according to the standard procedure mentioned in the literatures (Chattopadhyay et al. 2011). The test specimens were cut from composite sheets, dried at 60 ${ }^{\circ} \mathrm{C}$, cooled and weighed till the constant weight $\left(\mathrm{w}_{1}\right)$ was obtained. The specimens were then immersed in beaker containing distilled water at room temperature. The test specimens were removed from water, soaked with absorbent paper and weighed for three times. The weight was measured daily for one week, in every 2 days for two weeks and in 10 days for three weeks. The weight average $\left(\mathrm{w}_{2}\right)$ was calculated for each specimen. The weight was measured regularly for 50 days. The percentage increase in weight \% was calculated by using equation (2).

$\%$ Water Absorption $=\left(w_{2}-w_{1}\right) / w_{1} \times 100$

\section{Results and Discussion}

Fig. 1 shows the FTIR spectra of the neat and alkali treated bamboo flour. The alkali treatment of filler was carried out to remove the hemicelluloses and lignin from the BF. Neat and alkali treated BF clearly shows the characteristics peaks of cellulose at $3420 \mathrm{~cm}^{-1}, 2900$ $\mathrm{cm}^{-1}$ and $1050 \mathrm{~cm}^{-1}$ corresponding to the $\mathrm{OH}$ stretching, $\mathrm{CH}$ stretching and $\mathrm{C}-\mathrm{O}-\mathrm{C}$ stretching peak of pyranose ring structures respectively (Chattopadhyay et al. 2011). The strong carbonyl ( $\mathrm{C}=\mathrm{O}$, stretching) peak at $1740 \mathrm{~cm}^{-1}$ in neat BF is removed in alkali treated BF indicating the removal of acetyl group of hemicellulose from the fiber surface. A group of complex IR absorbance of lignin in the finger print region (1300$700 \mathrm{~cm}^{-1}$ ) might be due to the stretching of methoxy $\mathrm{O}-\mathrm{CH}_{3}$, ether $\mathrm{C}-\mathrm{O}-\mathrm{C}$, and $\mathrm{C}=\mathrm{C}$ stretching of aromatic ring containing compounds.

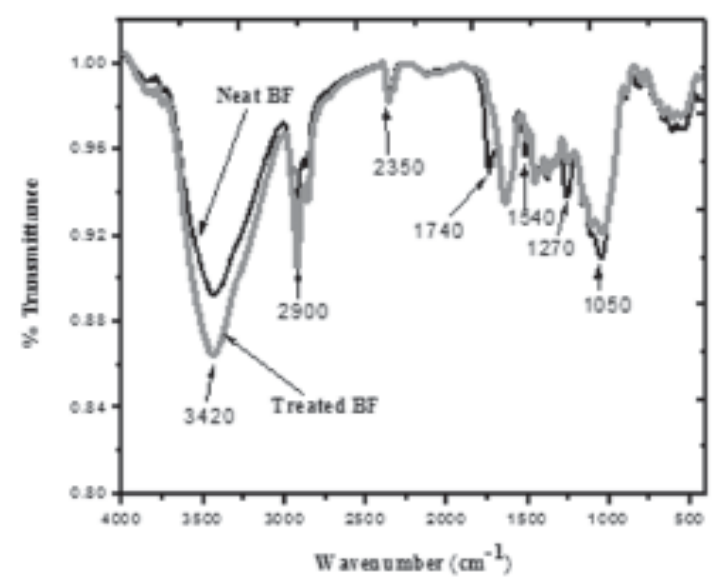

Fig. 1. Fourier transform infrared (FTIR) spectra of neat and treated BF

The lignin peaks at $1540 \mathrm{~cm}^{-1}, 1270 \mathrm{~cm}^{-1}$ in neat BF due to the aromatic $\mathrm{C}=\mathrm{C}$ stretching and aromatic ether $\mathrm{C}$ $\mathrm{O}-\mathrm{C}$ stretching are much reduced in treated $\mathrm{BF}$ due to the removal of lignin after the alkali treatment (Agarwal et al. 2009, Yang et al. 2007). Further the increase in the intensity of the $\mathrm{OH}$ stretching peak at $3420 \mathrm{~cm}^{-1}$ and $\mathrm{CH}$ stretching peak at $2900 \mathrm{~cm}^{-1}$ in TBF also represents the increase in the cellulose content after the delignification. 
The effect of the alkali treatment on morphology of the BF is clearly observed in the SEM micrographs shown in Fig. 2. In alkali treated BF cellulose microfibrils are regularly aligned and distinctly visible as compared with the neat BF. The clear cellulose microfibrils in treated BF form the bundles of about 10 ìm in size. The microfibers might appear even finer if the conditions of the alkali treatment were optimised.
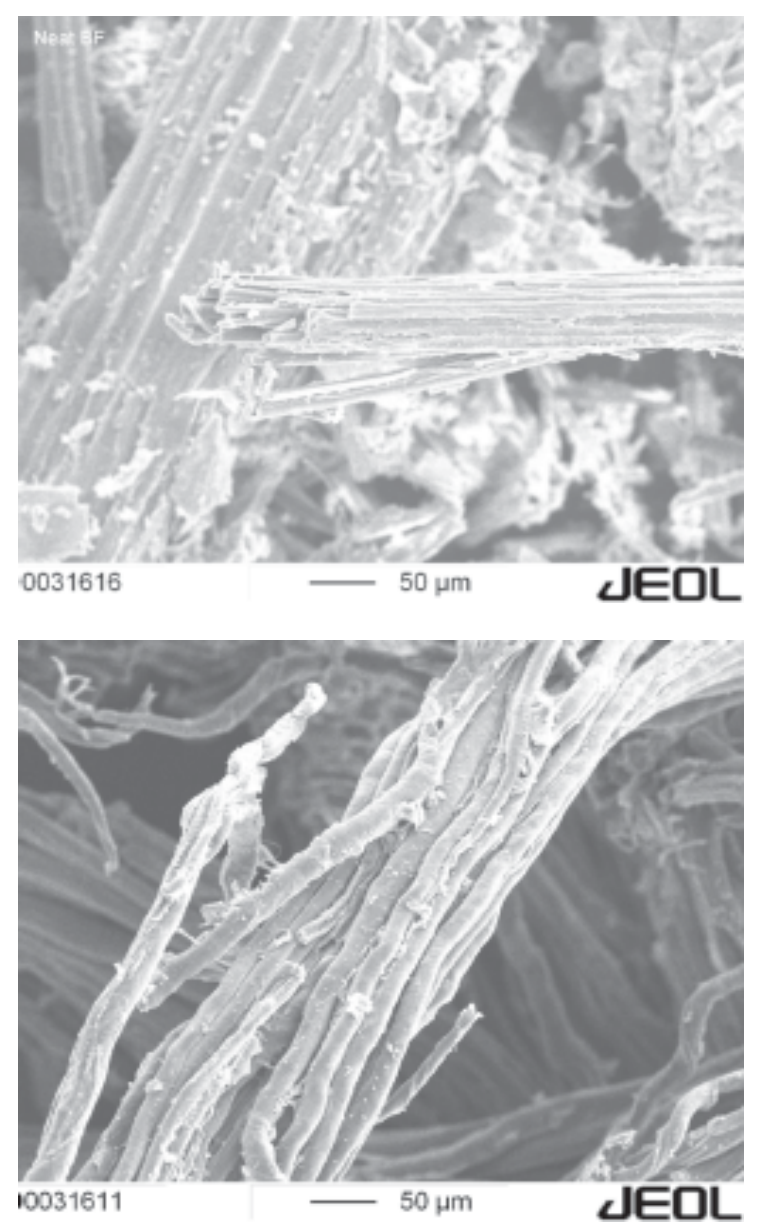

Fig. 2. Representative SEM images of neat and treated BF

The FTIR spectra of PP/BF composites (60/40 compositions) with neat (BF) and treated bamboo flour (TBF) compared with PP are shown in Fig. 3. The intense peak at $2960 \mathrm{~cm}^{-1}$ and around $1460 \mathrm{~cm}^{-1}$ are the characteristic peaks of the $\mathrm{CH}$ stretching and $\mathrm{C}-\mathrm{CH}_{3}$ stretching of polypropylene. Similar peaks are also observed in the spectra of the composites. Almost similar peaks are observed in neat and alkali treated BF/PP composites. The spectra of composites in Fig. 3 shows peaks corresponding to the polypropylene as well as BF. Clear peak shifts are not observed in composites. It implies that the physical mixing of filler in composite is homogeneous but chemically it is weak.

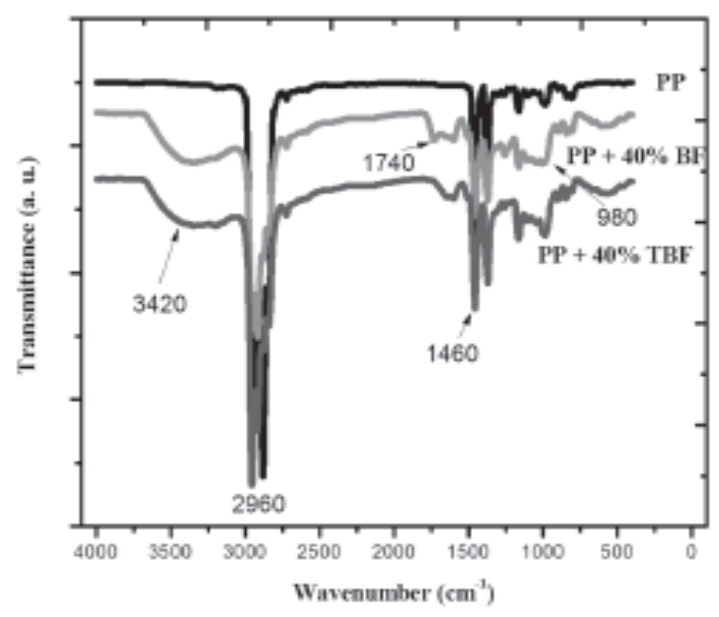

Fig. 3. Fourier transform infrared (FTIR) spectra of PP/ BF composite (60/40 composition) compared with neat $\mathrm{PP}$

Tensile stress strain curves of PP/BF composites of 80/20, 60/40 compositions with neat and alkali treated $\mathrm{BF}$ are shown in Fig. 4. The strain of the composites has been presented only up to the $2 \%$ strain. All the samples except pure iPP were broken below $2 \%$ strain. The strain of polypropylene goes beyond the 300\% (curve is not shown) (Adhikari et al. 2012). The mechanical properties of the composites with respect to strain at break have decreased as the flour content increased. Further the slope of the stress strain curves

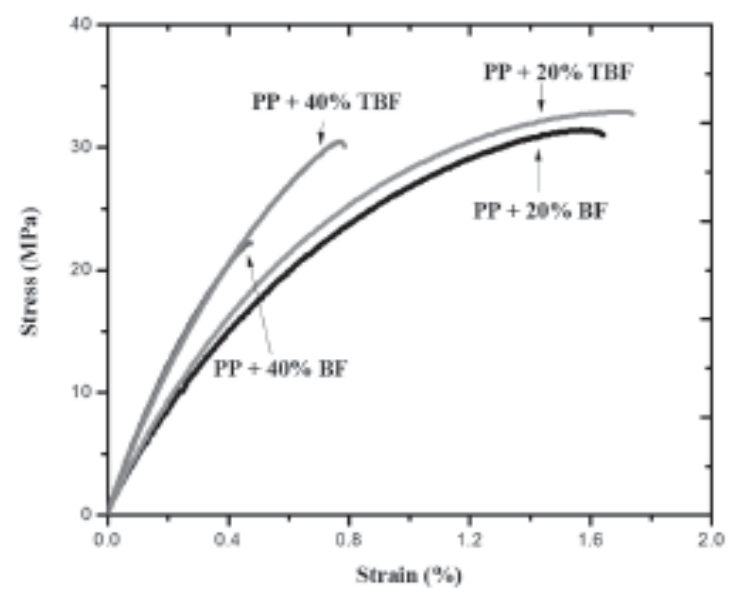

Fig. 4. Tensile stress-strain curve of PP/BF composites with neat (BF) and treated bamboo flour (TBF) with $80 / 20$ and $60 / 40$ compositions 
have increased with the increase in the flour content in the composites implying that the stiffness of the composites has also increased relative to the pure iPP. The strain and the elongation at break have improved in alkali treated BF composites compared with the neat $\mathrm{BF}$ composite and the effect is significant in the composite with 20 wt.- $\%$ filler. The yield stress and load bearing capacity of the composite was also found to increase in TBF composites as compared with the neat BF composites.

Fig. 5 represents the percentage of water absorption of PP/BF composites (with PP/BF compositions of 80/ 20 and 60/40) compared with the pure iPP. The curves in Fig. 5 show a clear trend of water absorption by composites. As the filler content is increased, the extent of water absorption is also increased that may be attributed to the increased cellulose content in the composites. Water is absorbed in the composites only due to the presence of the hydrophilic cellulose in BF. The percentage water absorption in pure PP is almost zero represented by straight line in the plot in Fig. 5. In composites, as the amount of neat BF is increased from 20 to 40 wt. - $\%$, the water absorption is increased by about $15 \%$ which is below $10 \%$ in the TBF composites. The results show that the treated BFs are more compatible with the iPP compared to the neat BF.

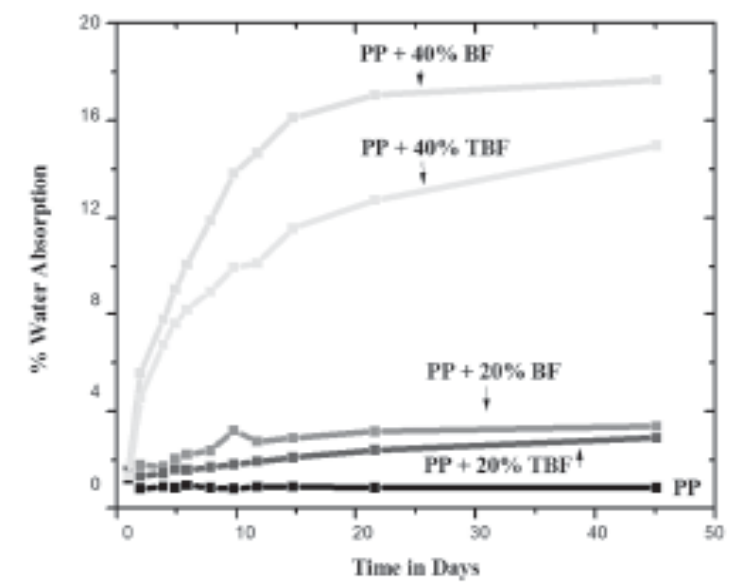

Fig. 5. Water absorption of the PP/BF composites of $80 / 20$ and $60 / 40$ composition of neat and treated bamboo flour

New kinds of composite materials based on isotactic polypropylene (iPP), one of the commercially available commodity plastics, and bamboo flour were fabricated via melt mixing. The filler used was either neat or that treated with alkali solution. The samples were characterized by different techniques such as infrared (IR) spectroscopy, electron microscopy, and tensile testing.

The alkali treated bamboo flour (TBF) has the fine microfibriller structures compared to the untreated flour. Hence, the TBF is more compatible with the polypropylene in its composites which might have resulted from the increased interfacial interaction due to larger surface to volume ratio of the treated filler. As a result, the tensile properties of the composites were found to improve with TBF as filler. The water absorption capacity of the composites was found to increase with the filler content in general. In case of the TBF, however, the increment was found to be lower than that in the composites with neat BF. The observation can be attributed to the enhanced compatibility of the TBF with iPP matrix.

The high filler loaded composites are found to be more biodegradable due to the high filler content. The development of such composites can contribute to save the environment due to biodegradation of the composites and reducing the use of commercial plastics. The bamboo flour reinforced polypropylene composites are tougher and stiffer hence the composites can be used mainly for low load bearing applications like house insulation (parquet flooring and carpeting), making packets, boxes and so others. The elastic property of the composite materials thus can be achieved if the chemical treatment of the flour and the processing conditions could be optimized so that the materials also would also be useful for high load bearing applications.

\section{Acknowledgements}

We thank University Grants Commission (UGC), Nepal for providing the Ph.D. research fellowship to NLB and Faculty Research Grant to RA. Thanks also go to Prof. Goerg H. Michler, Institute of Physics, MartinLuther University Halle-Wittenberg, Germany for providing support to use Scanning Electron Microscopy (SEM) investigations.

\section{References}

Adhikari, R., N.L. Bhandari, H.L. Hai, H.J. Radusch, G.H. Michler, M.R. Garda and J.M. Saiter. 2012. Thermal, mechanical and morphological behavior of poly(propylene)/wood flour composites. Macromolecular Symposia 315: 24-29. 
Nepal Journal of Science and Technology Vol. 13, No. 1 (2012) 95-100

Agarwal, U.P. and R.S. Reiner. 2009. Near-IR surfaceenhanced Raman spectrum of lignin. Journal of Raman Spectroscopy 40: 1527-1534.

Bledzki, A.K. and J. Gassan. 1999. Composites reinforced with cellulose based fibers. Progress of Polymer Science 24: 221-274.

Bledzki, A.K. and V.E. Sperber. 2008. $7^{\text {th }}$ Global WPC and natural fiber composites congress and exhibition. Scientific Presentations. Kassel, Germany.

Bogoeva-Gaceva, G., M. Avella, M. Malinconico, A. Buzarovska, A. Grozdanov, G. Gentile and M.E. Errico. 2007. Natural fiber eco-composites. Polymer composites 28 (1): 98-107.

Bourmaud, A. and C. Baley. 2007. Investigations on the recycling of hemp and sisal fiber reinforced polypropylene composites. Polymer Degradation and Stability 92: 1034-1045.

Chattopadhayay, S.K., R.K. Khandal, R. Uppaluri and A.K. Ghoshal. 2011. Bamboo fiber reinforced polypropylene composites and their mechanical, thermal and morphological properties. Journal of Applied Polymer Science 119: 1619-1626.

John, M.J. and R.D. Anandjiwala. 2008. Recent developments in chemical modification and characterization of natural fiber-reinforced composites. Polymer Composites 29(2): 187-207.

Joseph, P.V., K. Joseph and S. Thomas. 1999. Effect of processing variables on the mechanical properties of sisal-fiber-reinforced polypropylene composites. Composites Science and Technology 59: 1625-1640.

Kalaprasad, G., B. Francis, S. Thomas, C.R. Kumar, C. Pavithran, G. Groeninckx, S. Kumar, V. Chaoudhary and R. Kumar. 2010. Study on the compatibility of unbleached and bleached bamboo-fiber with LLDPE matrix. Journal of Thermal Analysis and Calorimetry
102: $751-761$

Li, Y., Y.W. Mai and L. Ye. 2000. Sisal fiber and its composites: a review of recent developments. Composites Science and Technology 60: 2037-2055.

Mormann, W. 2003. Silylation of cellulose with hexamethyldisilazane in ammonia-activation, catalysis, mechanism and properties. Cellulose 10: 271-281.

Nachtigall, S.M.B., G.S. Cerveria and S.M.L. Rosa. 2007. New polymeric-coupling agent for polypropylene/ wood-flour composites. Polymer Testing 26: 619-628.

Razi, P.S., A. Raman and R. Portier. 1997. Studies on mechanical properties of wood-polymer composites. Journal of Composite Materials 31: 2391-2401.

Rowell, R. M. 2005. Chemical modification of wood. In: Handbook of Wood Chemistry and Wood Composites (Ed R. M. Rowell), Taylor \& Francis. CRC Press, USA.

Saheb, D.N. and J.P. Jog. 1999. Natural fiber polymer composites: A review. Advances in Polymer Technology 18: 351-363.

Sperling, L.H. 2006. Mechanical behaviors of polymers. In: Introduction to Physical Polymer Science, Four ${ }^{\text {th }}$ ed. Wiley Inter Science Publication, New York, USA, 477 p.

Wu, J., D. Yu, C. Chan, J. Kim and Y. Mai. 2000. Effect of fiber pre-treatment condition on the interfacial strength and mechanical properties of wood fiber/PP composites. Journal of Applied Polymer Science 76: 1000-1010.

Yang, H., R.Yan, H. Chen, D.H. Lee and C. Zheng. 2007. Characteristics of hemicellulose, cellulose and lignin pyrolysis. Fuel 86: 1781-1788.

Zaini, M.J., M.Y.A. Fuad, Z. Ismail, M.S. Mansor and J. Mustafah. 1996. The effect of filler content and size on the mechanical properties of polypropylene/oil palm wood flour composites. Polymer International 40: 5155. 